\title{
Age-Related Incidence of Cervical Spondylosis in Residents of Jeju Island
}

\author{
Myung-Sang Moon, Min-Geun Yoon, Bong-Keun Park, Min-Suk Park \\ Department of Orthopedic Surgery and Traumatology, Cheju Halla General Hospital, Jeju, Korea
}

\section{Study Design: Cervical spine radiograms of 460 Jeju islanders.}

Purpose: To investigate the age-matched incidences and severity of the cervical disc degeneration and associated pathologic findings. Overview of Literature: Several related studies on the incidences of disc and Luschka's and facet joint degeneration have provided some basic data for clinicians.

Methods: Cervical radiographs of 460 (220 males and 240 females) patients in their fourth to ninth decade were analyzed. Ninety patients in their third decade were excluded because of absence of spondylotic findings.

Results: Overall incidence of cervical spondylosis was $47.8 \%$ (220 of 460 patients). The percentile incidences of spondylosis in the fourth, fifth, sixth, seventh, eighth and ninth decade was 13.2\% (10 of 76 patients), 34.6\% (37 of 107 patients), $58.9 \%$ (66 of 112 patients), 58.8\% (50 of 85 patients), $70.3 \%$ (45 of 64 patients) and $75.0 \%$ (12 of 16 patients), respectively. The percentile incidences of one, two, three, four and five level spondylosis among 220 spondylosis patients was $45.5 \%$ ( $n=100), 34.1 \%(n=75), 15.0 \%$ ( $n=33$ ), $4.5 \%(n=10)$, and $0.9 \%(n=2)$. Severity of disc degeneration ranged from \pm to ++++ , and was \pm in $6.0 \%$ (24 segments), + in $49.6 \%$ (198 segments), ++ in $35.3 \%$ (141 segments), +++ in $9.0 \%$ (36 segments) and ++++ in $0.25 \%$ (one segment). Spurs and anterior ligament ossicle formed at the spondylotic segments, mostly at C4 6. The rate of posterior corporal spurs formation was very low. Olisthesis and ossification of the posterior longitudinal ligament were rarely combined with spondylosis. Cervical lordotic curve decreased gradually according to the progress of severity of spondylosis.

Conclusions: The incidence of cervical spondylosis and number of spondylotic segments increase, and degeneration gradually becomes more severe with age.

Keywords: Spondylosis; Cervical; Incidences; Severity; Spurs

\section{Introduction}

Senescent cervical spondylosis is a generalized natural aging process affecting all levels. It involves a sequence of degenerative changes in spinal structure. Spondylosis is a degenerative disease of both the disk and zygoapophyseal joints, which features narrowing of the disk and neural foramina and osteophyte formation. The end results are radiculopathy and ligamental instability [1-6].

The first manifestation of aging in the spinal column is spondylosis in the intervertebral disk in the third through fifth decades. Cervical spondylosis is essentially a degenerative disorder that begins in the disk and progresses with age to involve more than one disk. This disorder is

\footnotetext{
Received Jan 25, 2016; Revised Mar 5, 2016; Accepted Mar 22, 2016

Corresponding author: Myung-Sang Moon

Department of Orthopedic Surgery and Traumatology, Cheju Halla General Hospital,

65 Doryungro (Yeon-dong), Jeju 63127, Korea

Tel: +82-2-780-5387, Fax:+82-2-785-6065, E-mail: msmoonos@hotmail.com
} 
common in Korea and elsewhere [1-4,7-9].

Over a century ago, bars and ridges arising from the intervertebral area projecting backward (posterior corporal edge spurs) narrowing the spinal canal had been described as a potential cause of spinal cord compression $[1,2]$. Clinical symptoms, particularly neurologic ones, have since been clarified. Studies a half-century ago revealed the common prevalence of cervical spondylosis in elderly people $[7,8]$. The studies documented radiologic changes indicative of cervical spondylosis in half of those over 50 years of age and three-quarters of those over 65 years of age. As well, $40 \%$ of people over 50 years of age had some limitation of neck movement, and some had neurologic abnormalities that often preceded symptoms [8]. Another study reported that $75 \%$ of subjects in their seventh decade of life displayed some degenerative changes in the cervical spine [5].

A 1969 conducted in England reviewed cervical spine $\mathrm{X}$-rays of 1,803 males and 1,572 females aged 15 years and over $(86 \%$ and $85 \%$, respectively, of groups in a population survey) [10]. Forty two percent of males and $37 \%$ of females had definite evidence of disc degeneration of the cervical spine, but this was minimal in $21 \%$ and $24 \%$ of subjects, respectively. Cervical disc degeneration was related to neck-shoulder brachial pain in both sexes, but was significant only in those with moderate or severe disease and narrowed discs. Degeneration was mainly related to a past episode of pain or repeated episode of pain. However, a history or signs of nerve root involvement was found only in $1.7 \%$ of 662 subjects with moderate to severe cervical disc degeneration. Obvious symptoms and signs of cervical myelopathy were not found [10]. Prior studies conducted in Korea in the 1970s and 1980s involved the analysis of simple radiographs of 107 aged Koreans' cervical spines to detect the spondylosis [11], cervical neural canal dimension measurement [12], and Pavlov ratio [13]. The data have not proven influential in treatment decisions by Korean spine surgeons [11-16].

Spondylotic changes, such as narrowing of the disk and osteophytes, predominated at the lower disk levels including C5-6 and C6-7, where the range of motion decreased with advancing age. Conversely, upper disc levels, such as C3-4 and C4-5, showed a comparatively greater mobility and vertebral "olisthesis", particularly "retrolisthesis" in extension [17].

The lack of recent information and the under-recognition of the foregoing information demanded another look at the issue, and was the reason for the present prospective study.

\section{Materials and Methods}

This prospective study analyzed simple cervical radiograms of 460 adult patients (220 males and 240 females) in their fourth decade of life and beyond taken from July 2013 to May 2015. Seventy six patients (16.5\%) were in their fourth decade, 107 (23.3\%) were in their fifth decade, $112(24.3 \%)$ were in their sixth decade, 85 (18.5\%) were in their seventh decade, 64 (13.9\%) were in their eighth decade and 16 patients (3.5\%) were in their ninth decade. Cases of diffuse idiopathic skeletal hyperostosis, and congenital synostosis and stenosis were excluded. There were no healthy volunteers. Age- and gender-matched incidence of cervical spondylosis and its severity on radiograms were sought. The radiographic findings that were assessed were reduction of disc space, anterior and posterolateral spurs, anterior ligament ossicle, end-plate sclerosis adjacent to degenerative disc, abnormalities of neurocentral and zygoapophysial joints, ossification of the posterior longitudinal ligament (OPLL) and relationship between disc space narrowing and osteophyte and ossicle in anterior ligament. Simple cervical radiograms were taken in four directions (anteroposterior, lateral and both oblique views). To reduce misinterpretation and to prove the reading accuracy, computed tomography (CT) and/ or magnetic resonance imaging (MRI) were taken when essentially needed, and for patients who were the surgical candidates. MRI classification of disc degeneration and gene polymorphisms for spurs were not part of the study design. Image findings indicative of disc degeneration included disc space narrowing, corporal edge spurs, ossicle in anterior corporal ligament, olisthesis and sagittal alignment of cervical spine. Disc space narrowing was expressed by five grades of severity:,$\pm<20 \%$ disc height loss; +, $21 \%$ to $40 \%$ loss; ++, $41 \%$ to $60 \%$ loss;,$+++ 61 \%$ to $80 \%$ loss and,$++++ 81 \%$ to $100 \%$ loss. Formed spurs were classified ( 1 to 3 ) by their origin and shape: 1 , sharp anterior inferior corporal edge spur (uncinate); 2 , claw spur (paired and unpaired) and 3, traction spur. However, to simplify the presentation the numbers of all types of spurs were summed up as a type. Anterior ligament ossicle and ossification of anterior longitudinal ligament (OALL) formed at the disc level were also observed, and their role in disc height maintenance were assessed. Olisthesis and 
OPLL also were observed.

\section{Results}

\section{Spondylosis}

The overall incidence of all severities of spondylosis was $47.8 \%$. The incidence in the fourth, fifth, sixth, seventh, eighth and ninth decade of life was $13.2 \%$ (10 of 76 patients), 34.6\% (37 of 107 patients), 58.9\% (66 of 112 patients), $58.8 \%$ (50 of 85 patients), $70.3 \%$ (45 of 64 patients) and $75.0 \%$ (12 of 16 patients), respectively (Table 1, Figs. 1-6). The average overall incidence of mono-, bi-, tri-, quadri- and penta-segment spondylosis was $45.5 \%$ (100 patients), 34.1\% (75 patients), 15.0\% (33 patients), $4.5 \%$ (10 patients) and $0.9 \%$ (two patients), respectively

Table 1. Age-matched radiographic incidences of cervical disc degeneration (n: 460 patients)

\begin{tabular}{lcc} 
Age (decade) & Material no. (subject patients) & $\begin{array}{c}\text { Patient no. with disc degeneration } \\
\text { (percentile incidence) }\end{array}$ \\
\hline 4th & $76(16.5)$ & $10(13.2)$ \\
\hline Male/Female & $52(68.4) / 24(31.6)$ & $8(80.0) / 2(20.0)$ \\
\hline th & $107(23.3 \%)$ & $37(34.6)$ \\
\hline Male/Female & $49(45.8) / 58(54.2)$ & $19(51.4) / 18(48.6)$ \\
\hline 6th & $112(24.3)$ & $66(58.9 \%)$ \\
\hline Male/Female & $57(50.9) / 55(49.1)$ & $36(54.5) / 30(45.5)$ \\
\hline 7th & $85(18.5)$ & $50(58.8)$ \\
\hline Male/Female & $35(41.2) / 50(58.8)$ & $24(48.0) / 26(52.0)$ \\
\hline 8th & $64(13.9)$ & $45(70.3 \%)$ \\
\hline Male/Female & $21(32.8) / 43(67.2)$ & $16(35.6 \%) / 29(64.4 \%)$ \\
\hline 9th & $16(3.5)$ & $12(75.0 \%)$ \\
\hline Male/Female & $6(37.5) / 10(62.5)$ & $5(41.7) / 7(58.3)$ \\
\hline Total & $460(100)$ & $108(49.1): 108$ out of 220 \\
\hline Male & $220(47.8)$ & $112(46.7): 112$ out of 240 \\
\hline Female & $240(52.2)$ & \\
\hline
\end{tabular}

Values are presented as number (\%).

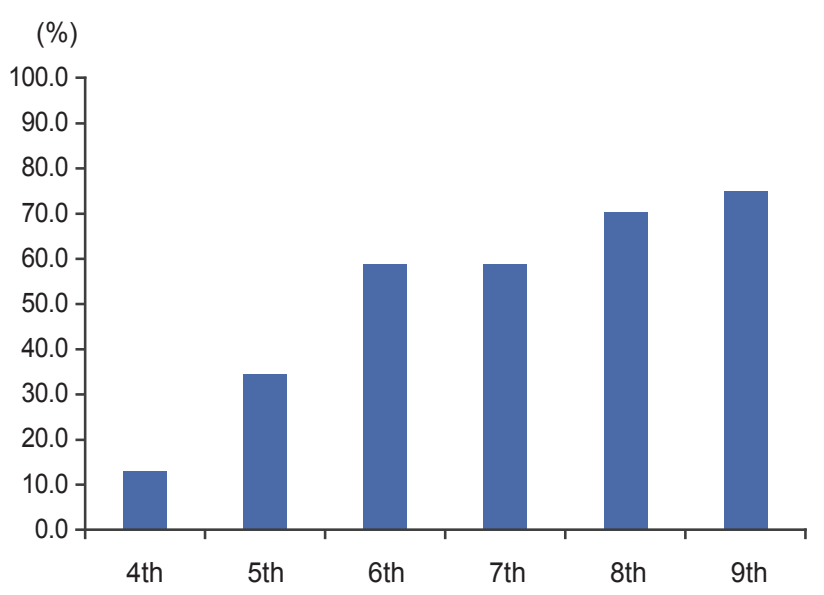

Fig. 1. Histograms of age-matched percentile incidences of spondylosis in 220 patients.
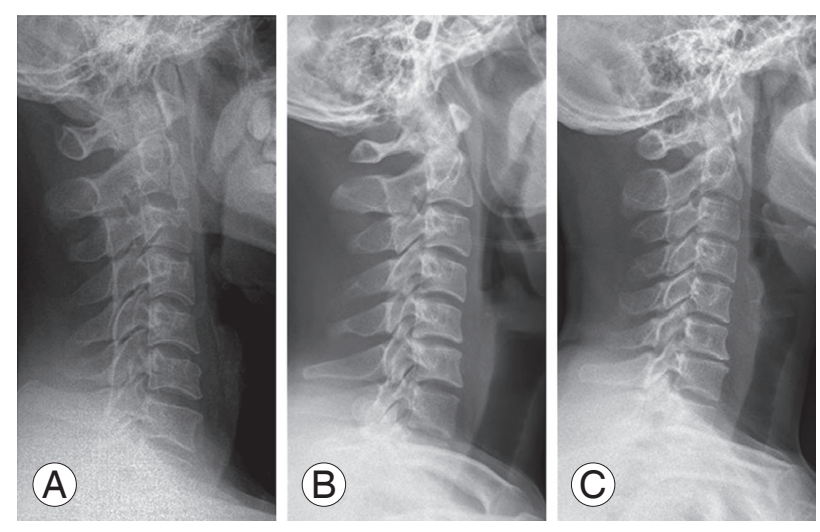

Fig. 2. Data from patients in their fourth decade of life. (A) Cervical spine with normal disc space in spite of flattened curve. (B) Slightly flattened curve with slightly narrowed disc spaces (C4-5 and C5-6) without anterior corporal spurs. (C) Flattened curve with multiple narrowed disc spaces (C3-7) with early small corporal edge spurs (C5-6 and (6-7). 

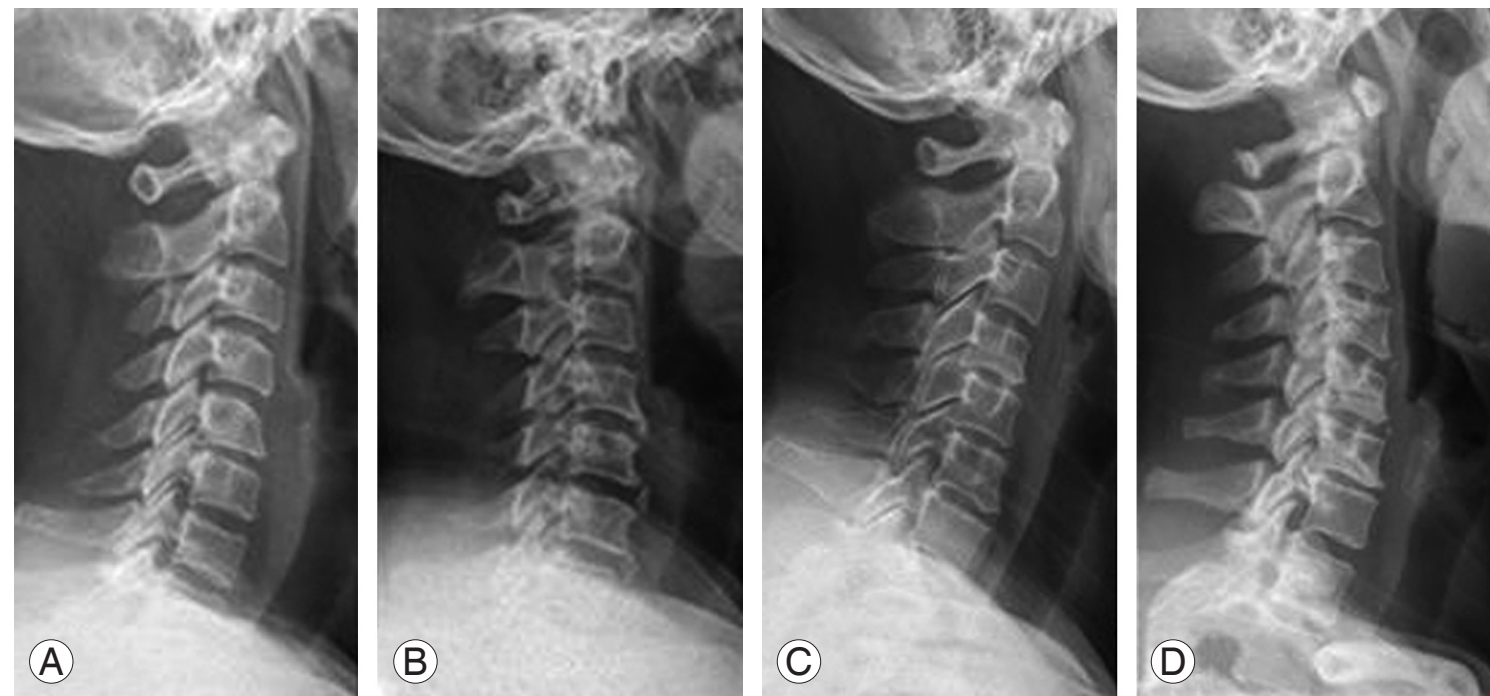

Fig 3. Data from patients in their fifth decade of life. (A) Cervical radiograms shows narrowed C5-6 disc space with slight curve flattening and projected anteroinferior cortical edge. (B) Well-maintained disc height with traction spurs and ossified annulus fibrosis and anterior longitudinal ligament (C2-3, C4-5, C5-6). (C) Flattened cervical curve with narrow discs of C4-5, C5-6, and C6-7 without spurs. (D) Paired small anterior spurs with slightly narrowed disc spaces at C4-5 and C5-6.
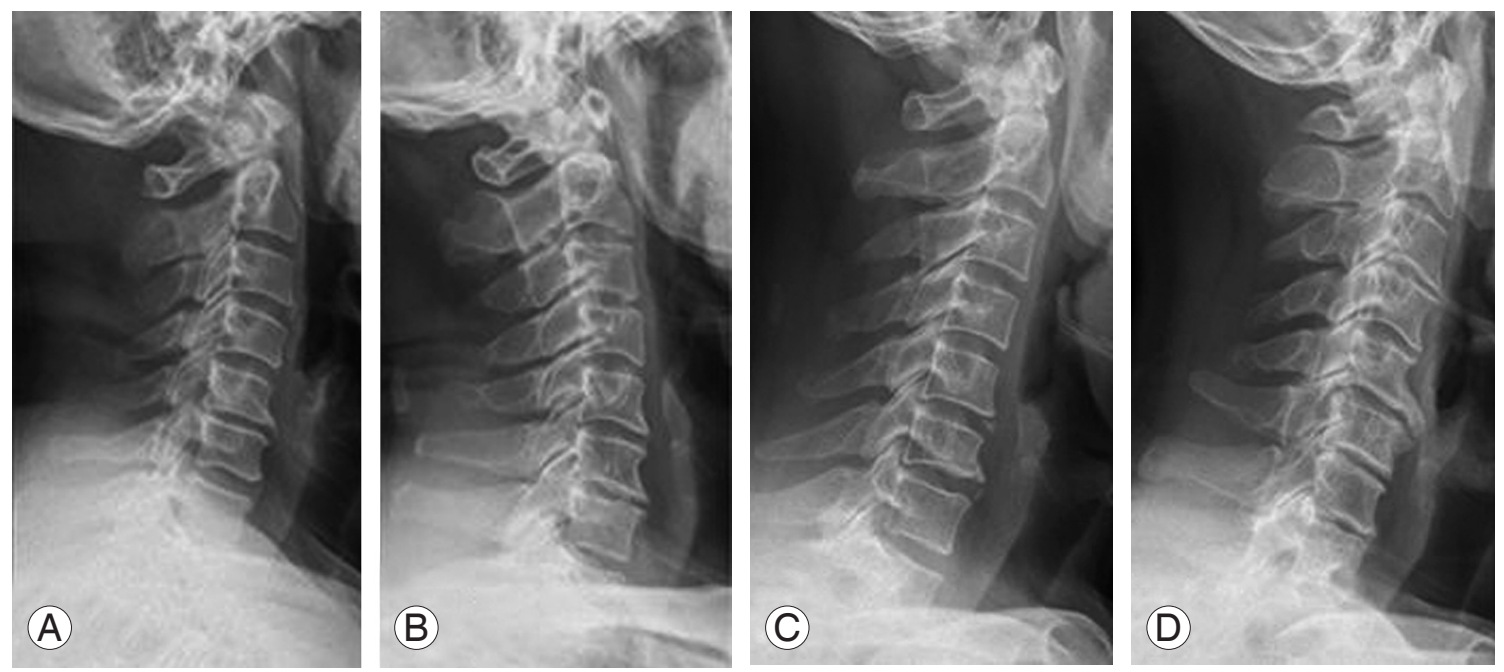

Fig 4. Data from patients in their sixth decade of life. (A) Moderately advanced disc degeneration with narrowing and claw spur at C5-6. (B) Slightly collapsed disc height at C5-6 and C6-7 with small claw spurs and flattened curve. (C) Flattened curve with dotted ossification of anterior corporal ligament at two levels (C5-6 and C6-7) without disc collapse. (D) Multilevel disc degeneration with collapse and small anterior spurs (C3-4, C4-5, C5-6, C6-7, C7-T1).

(Table 2). The incidence of mono-segment spondylosis in the fourth, fifth, sixth, seventh, eighth and ninth decade of life was $60.0 \%$ ( 6 of 10 spondylosis cases), $48.6 \%$ (18 of 37 spondylosis cases), $45.5 \%$ (30 of 66 spondylosis cases), $48.0 \%$ ( 24 of 50 spondylosis cases), 40.0\% (18 of 45 spondylosis cases) and $33.3 \%$ (four of 12 spondylosis cases), respectively. The incidence of bi-segment spondylosis in the fourth, fifth, sixth, seventh, eighth and ninth decade of life was $40.0 \%$ (four of 10 spondylosis cases), $37.8 \%$
(14 of 37 spondylosis cases), 39.4\% (26 of 66 spondylosis cases), $26.0 \%$ (13 of 50 spondylosis cases), 26.7\% (12 of 45 spondylosis cases) and 50.0\% (six of 12 spondylosis cases), respectively. The incidences of three-segment spondylosis in the fourth, fifth, sixth, seventh, eighth and ninth decade of life was zero, $13.5 \%$ (five of 37 spondylosis cases), $9.1 \%$ (six of 66 spondylosis cases), $18.0 \%$ (nine of 50 spondylosis cases), $26.7 \%$ (12 of 45 spondylosis cases) and $8.3 \%$ (one of 12 spondylosis cases), respectively. The in- 

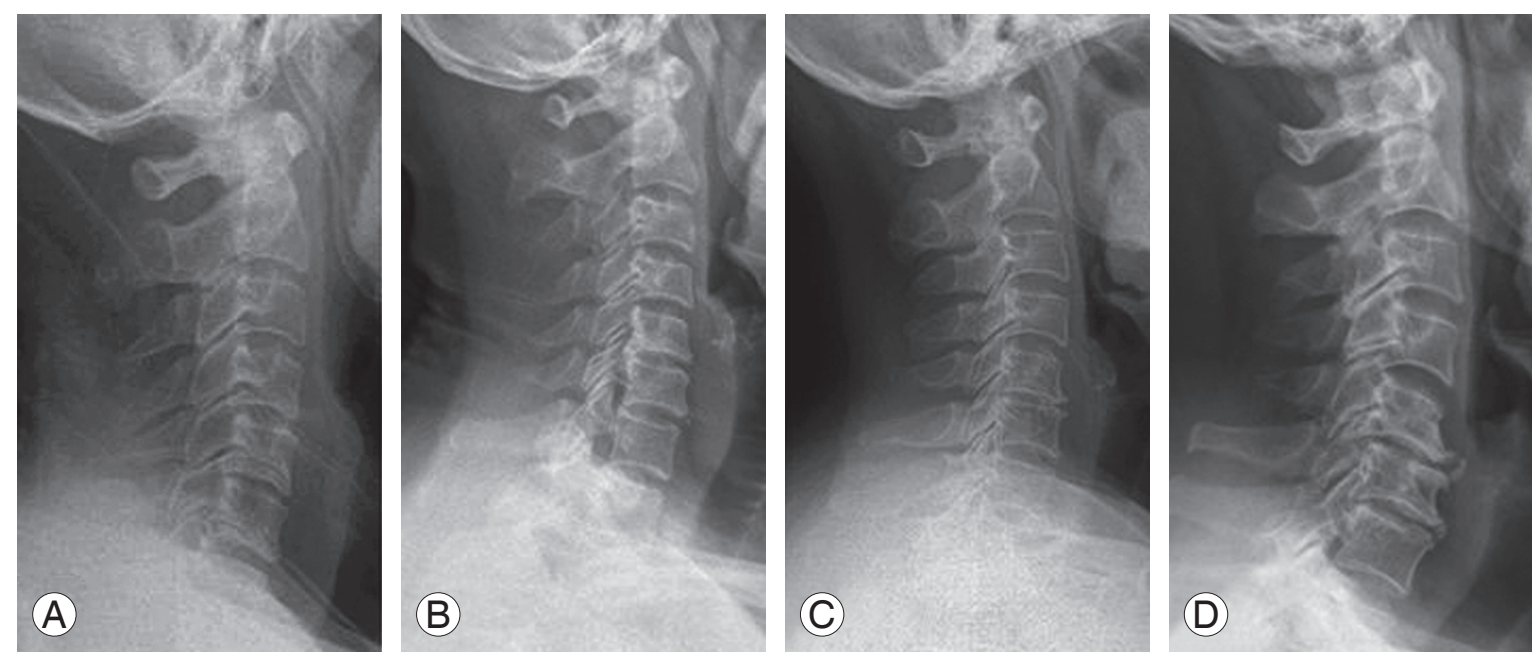

Fig. 5. Data from patients in their seventh decade of life. (A) C5-6 monosegment disc narrowing is seen. (B) Mild C5-6 disc collapse with visible posterior corporal spurs is seen which made the transverse corporal bony bar. (C) Marked disc collapse at C5-6 with claw spurs is seen. (D) Advanced disc degeneration at two levels (C5-6 and C6-7) with large anterior traction spurs and posterior transverse corporal bony spurs is seen.
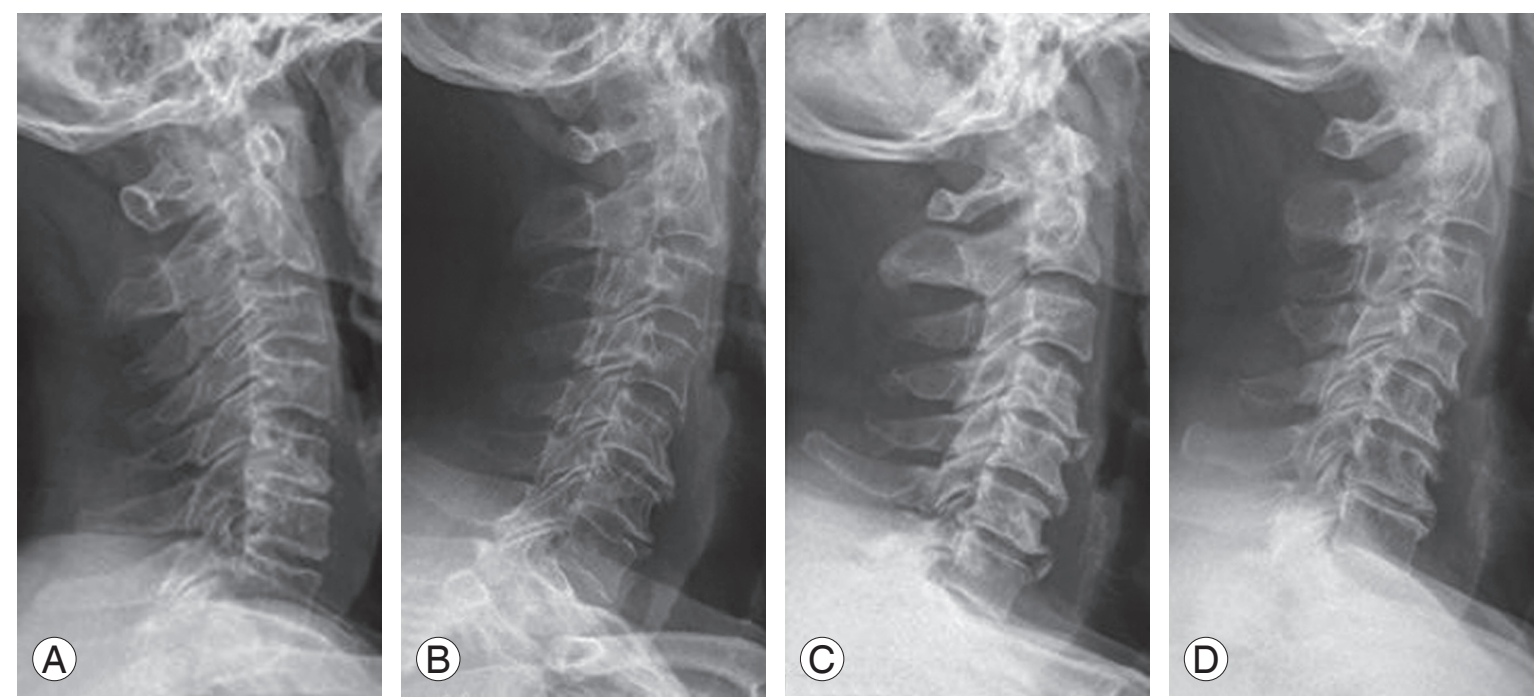

Fig. 6. Data from patients in their eighth decade of life. (A) Disc collapse at C5-6 without spurs. (B) Disc collapse at C5-6 and C6-7 with dotted ossification of anterior corporal ligament at three levels (C4-5, C5-6, and C6-7). (C) Moderate disc degeneration and collapse with anterior and posterior traction spurs are seen. (D) Loss of lordosis due to disc collapse at three levels (C4-5, C5-6, and C6-7) is seen.

cidences of four-segment spondylosis in the fourth, fifth, sixth, seventh, eighth and ninth decade of life was zero, zero, $4.5 \%$ (three of 66 spondylosis cases), $8.0 \%$ (four of 50 spondylosis cases), $4.4 \%$ (two of 45 spondylosis cases), and $8.3 \%$ (one of 12 adults), respectively. Five-segment spondylosis was found only in two cases; one each in the sixth and eighth decade of life at segments C2 to 7 (Figs. 1-6). The percentage of the patients with spondylosis, but not the severity, increased with age. Severity is assumed to be related with the initiation and observation times of spondylosis (Table 2, bottom column; Table $3,+++$ ).

\section{Severity of disc degeneration in each decade}

The data are summarized in Table 3 and Figs. 1 to 6. In 10 of 76 patients in their fourth decade with spondylosis, two segments had \pm change, nine segments had + change and three segments had ++ change. In 37 of 107 patients 
Table 2. Age-matched radiographic incidences of cervical spondylosis and numbers of spondylotic segment in each individual among 220 spondylosis patients out of 460 Korean adults

\begin{tabular}{|c|c|c|c|c|c|c|c|}
\hline \multirow{3}{*}{$\begin{array}{l}\text { No. of spondylic } \\
\text { segments }\end{array}$} & \multicolumn{7}{|c|}{ Age (decade) } \\
\hline & 4th (76 pts) & 5th (107 pts) & 6th (112 pts) & 7th (85 pts) & 8th (64 pts) & 9th (16 pts) & Total \\
\hline & $\begin{array}{l}\mathrm{n}=10 \\
(13.2)\end{array}$ & $\begin{array}{l}\mathrm{n}=37 \\
(34.6)\end{array}$ & $\begin{array}{c}n=66 \\
(58.9)\end{array}$ & $\begin{array}{l}\mathrm{n}=50 \\
(58.8)\end{array}$ & $\begin{array}{l}n=45 \\
(70.3)\end{array}$ & $\begin{array}{l}\mathrm{n}=12 \\
(75.0)\end{array}$ & $\begin{array}{l}n=220 \\
(47.8)\end{array}$ \\
\hline 1 Segment & $6(60.0)$ & $18(48.6)$ & $30(45.5)$ & $24(48.0)$ & $18(40.0)$ & 4 (33.3) & $100(45.5)$ \\
\hline 2 Segments & $4(40.0)$ & 14 (37.8) & $26(39.4)$ & $13(26.0)$ & $12(26.7)$ & $6(50.0)$ & 75 (34.1) \\
\hline 3 Segments & None & $5(13.5)$ & $6(9.1)$ & $9(18.0)$ & $12(26.7)$ & $1(8.3)$ & $33(15.0)$ \\
\hline 4 Segments & None & None & $3(4.5)$ & $4(8.0)$ & $2(4.4)$ & $1(8.3)$ & $10(4.5)$ \\
\hline 5 Segments & None & None & $1(1.5)$ & None & $1(2.2)$ & None & $2(0.9)$ \\
\hline $\begin{array}{l}\text { Total } \\
220 \text { patients (pts) }\end{array}$ & $\begin{array}{c}13.2 \% \\
10 / 76 \text { pts }\end{array}$ & $\begin{array}{c}34.6 \% \\
37 / 107 \text { pts }\end{array}$ & $\begin{array}{l}\text { 58.9\% } \\
66 / 112 \text { pts }\end{array}$ & $\begin{array}{c}58.8 \% \\
50 / 85 \text { pts }\end{array}$ & $\begin{array}{l}\text { 70.3\% } \\
45 / 64 \text { pts }\end{array}$ & $\begin{array}{c}75.0 \% \\
12 / 16 \text { pts }\end{array}$ & - \\
\hline
\end{tabular}

pts, patients.

Values are presented as number (\%).

Table 3. The average severity of disc degeneration of the spondylotic segment in each decade from fourth to ninth decade (n: 220 patients with spondylosis)

\begin{tabular}{|c|c|c|c|c|c|c|c|}
\hline & \multicolumn{7}{|c|}{ Patient no. with spondylosis and no. of spondylotic segment } \\
\hline & 4th & 5th & 6th & 7 th & 8th & 9th & Total \\
\hline No. of patients & $10(4.6)$ & $37(16.9)$ & $66(30.3)$ & $50(22.9)$ & $45(20.6)$ & $12(5.5)$ & 220 \\
\hline No. of spondylotic segments & 14 & 61 & 117 & 93 & 91 & 23 & 399 \\
\hline \multicolumn{8}{|l|}{ Severity of disc generation } \\
\hline \pm & $2(14.3)$ & $7(11.5)$ & $5(4.3)$ & $4(4.3)$ & $3(3.3)$ & $3(13.0)$ & $24(6.0)$ \\
\hline+ & $6(64.3)$ & $32(52.5)$ & $54(46.2)$ & $50(53.3)$ & 37 (40.7) & 15 (65.2) & 198 (49.6) \\
\hline++ & $3(21.4)$ & $21(34.4)$ & $48(41.0)$ & $28(30.1)$ & 36 (39.6) & 5 (21.7) & 141 (35.3) \\
\hline +++ & & $1(1.6)$ & $10(8.5)$ & $11(11.8)$ & $14(15.4)$ & & $36(9.0)$ \\
\hline++++ & & & & & $1(1.1)$ & & $1(0.25)$ \\
\hline
\end{tabular}

Values are presented as number $(\%)$.

\pm , disc height collapse, less than $20 \%$ of normal height; + , disc height collapse, between $21 \%-40 \%$ of normal height; ++ , disc height collapse, between $41 \%-60 \%$ of normal height; +++, disc height collapse, between $61 \%-80 \%$ of normal height; ++++, disc height collapse, between $81 \%-100 \%$ of normal height.

with spondylosis in their fifth decade of life, severity was \pm in seven segments, + in 33 segments, ++ in 21 segments and +++ in one segment. In 66 of 112 patients with spondylosis in their sixth decade of life, severity was \pm in five segments, + in 54 segments, ++ in 48 segments and +++ in 10 segments. In 50 of 85 patients with spondylosis in their seventh decade of life, severity was \pm in four segments, + in 50 segments, ++ in 28 segments and +++ in 11 segments. In 45 of 64 patients with spondylosis in their eighth decade of life, severity was \pm in three segments, + in 37 segments, ++ in 36 patients, +++ in 14 segments and ++++ in one segment. In 12 of 16 patients with spon- dylosis in their ninth decade of life, severity was \pm in three segments, + in 15 segments and ++ in five segments.

\section{Incidences of spur and anterior ligament ossicle formation}

Most of the spurs formed between C4-5 and C6-7. Anterior ligament ossicles also formed between $\mathrm{C} 3-\mathrm{T} 1$, and mostly at the C5-7 levels. Ossicle in anterior ligament in the fourth, sixth, seventh, eighth and ninth decade of life was evident were in zero, 32.4\% (12 segments), 36.4\% (24 segments), $64.0 \%$ (32 segments), 31.1\% (14 segments) and $25.0 \%$ (three segments), respectively (Table 4 ). Ossicle 


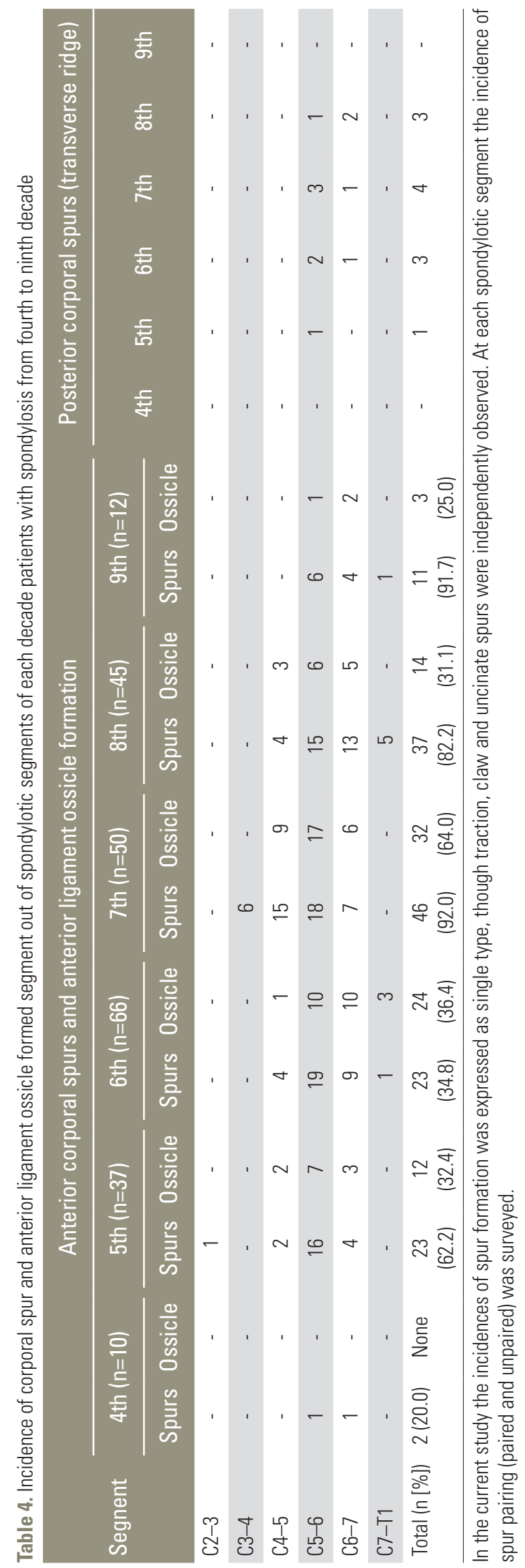

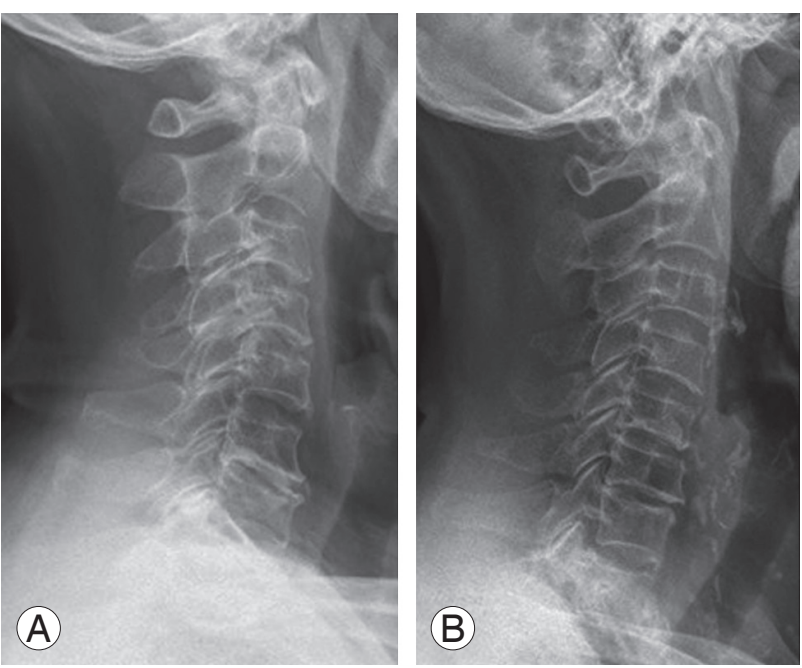

Fig. 7. Data from patients in their ninth decade of life. (A) Disc collapse at C6-7 with spur and a dotted anterior ligament ossification are seen. (B) Mild disc collapse at C5-6 and C6-7 with small spur at C6 inferior corporal edge spur is seen.

disc height was well maintained in most cases, but was not maintained in a few cases (Figs. 7, 8, 9G). Among the 460 patients in this study, only six had olisthesis (vertebral slip), which comprised two C5 antelisthesis (anterior slip) and four retrolisthesis (posterior slip; one at C3, 2=two at $\mathrm{C} 4$ and 1oneat $\mathrm{C} 5$ ) and OPLL in three patients. In a 58 year-old male, C4-5 monosegment OALL was observed (Table 5, Fig. 9G). No patient displayed true complete anterior bone bridge in ALL, even in cases with an ossicle in ALL.

\section{Cervical sagittal alignment}

Cervical sagittal curve gradually became flattened secondary to the progress of spondylosis in all patients, but was not related with age. The loss of cervical lordosis depended on the severity of disc degeneration and the numbers of degenerated disks (Figs. 2-10).

\section{Discussion}

The cervical spine is composed of four identical typical vertebrae with short bifid spinous process (third to sixth) and three atypical vertebrae (first, second, and seventh). The height of the typical vertebral body is greater posteriorly than anteriorly, and the normal cervical curve is due to disc configuration rather than to the vertebral bodies themselves. Cervical spondylosis is a manifestation of 

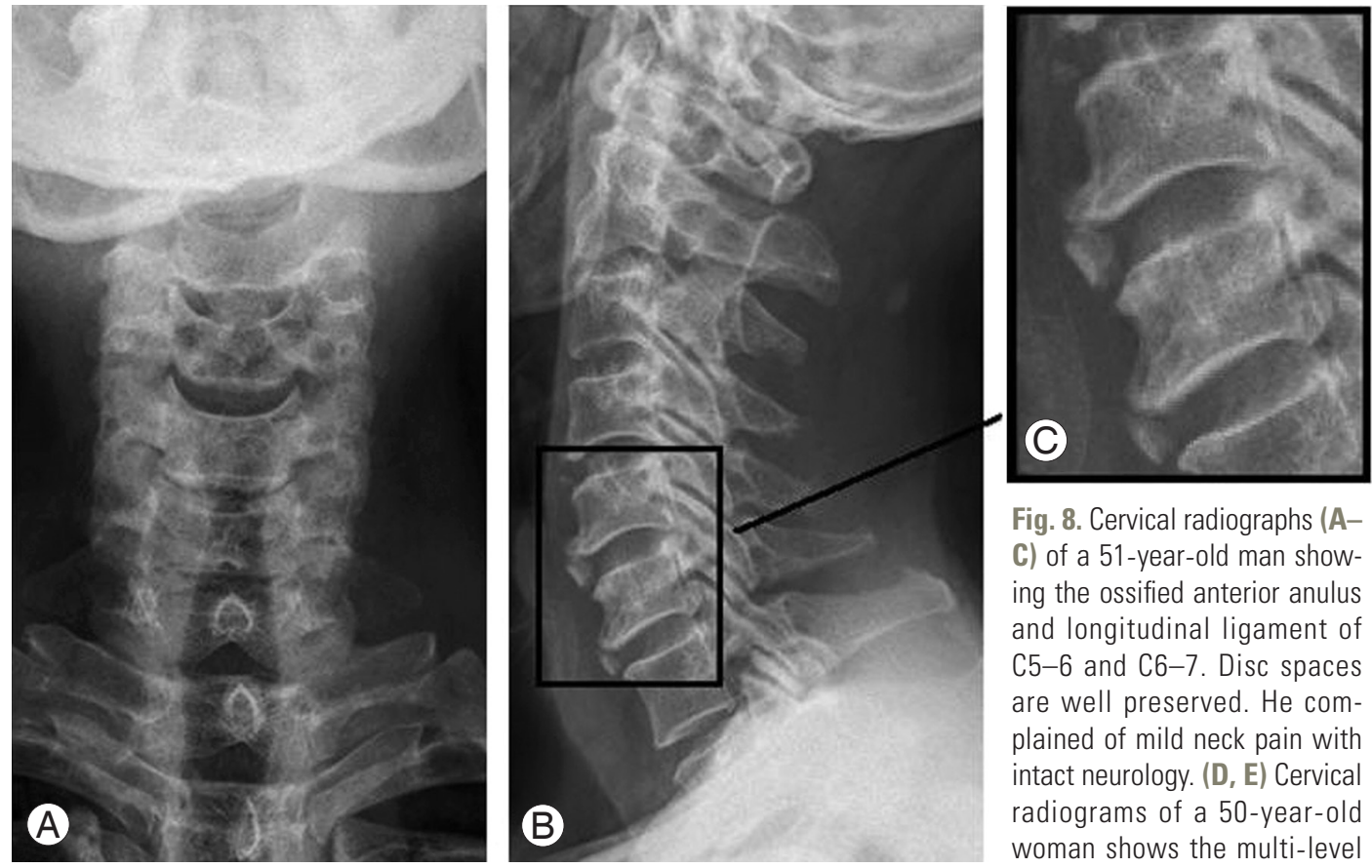

Fig. 8. Cervical radiographs (AC) of a 51-year-old man showing the ossified anterior anulus and longitudinal ligament of C5-6 and C6-7. Disc spaces are well preserved. He complained of mild neck pain with intact neurology. (D, E) Cervical radiograms of a 50 -year-old woman shows the multi-level
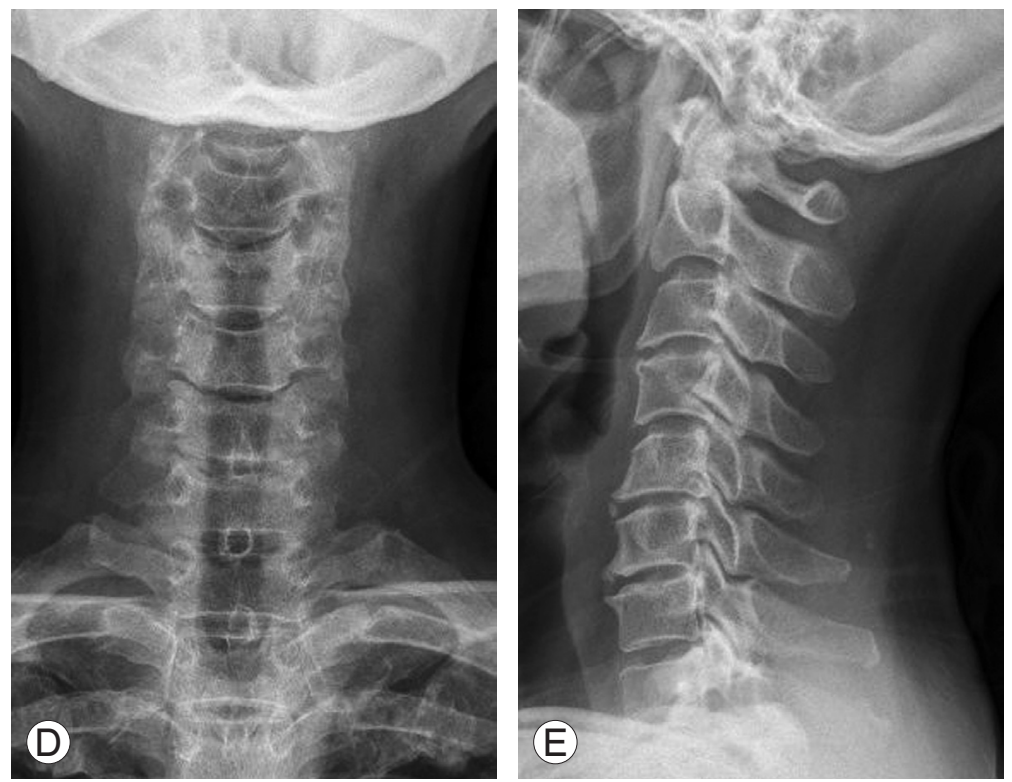
spondylosis and poterior corporal edge spur at C5-6 and C6-7 with some disk collapse in spite of the associated anterior ligament ossicle at C5-6.

the aging process, which includes both disc degeneration and diseases of Luschka's and facet joints, and is relatively common. Half of the population experiences degenerative arthritis in their life, and is present in nearly all (97\%) of people over 60 years of age. The condition becomes symptomatic in $50 \%$ of men and $25 \%$ of women [1-12,18-22]. Whether spondylitis should be considered a degenerative change or an age change may appear simply a matter of semantics. But the development of osteophytes can be viewed as a reactive and adaptive change that seeks to compensate for biomechanical aberrations. The cardinal feature of spondylosis is the development of osteophytes along the junction of vertebral bodies and their intervertebral discs $[5,21]$. Degenerative change can start even in the third decade of life, but was not found in the third decade patients in the current series. The degenerative changes initiate first at the intervertebral disc, Luschka's and facet joints in order $[4,14,16]$. Spurs found in the evolutional process of degeneration have been termed spondylosis by Epstein [20], marginal spondylosis by Borak [3] and osteophytosis by Collins. The main cause of disc space narrowing are degenerative changes of the Luschka's joints, 

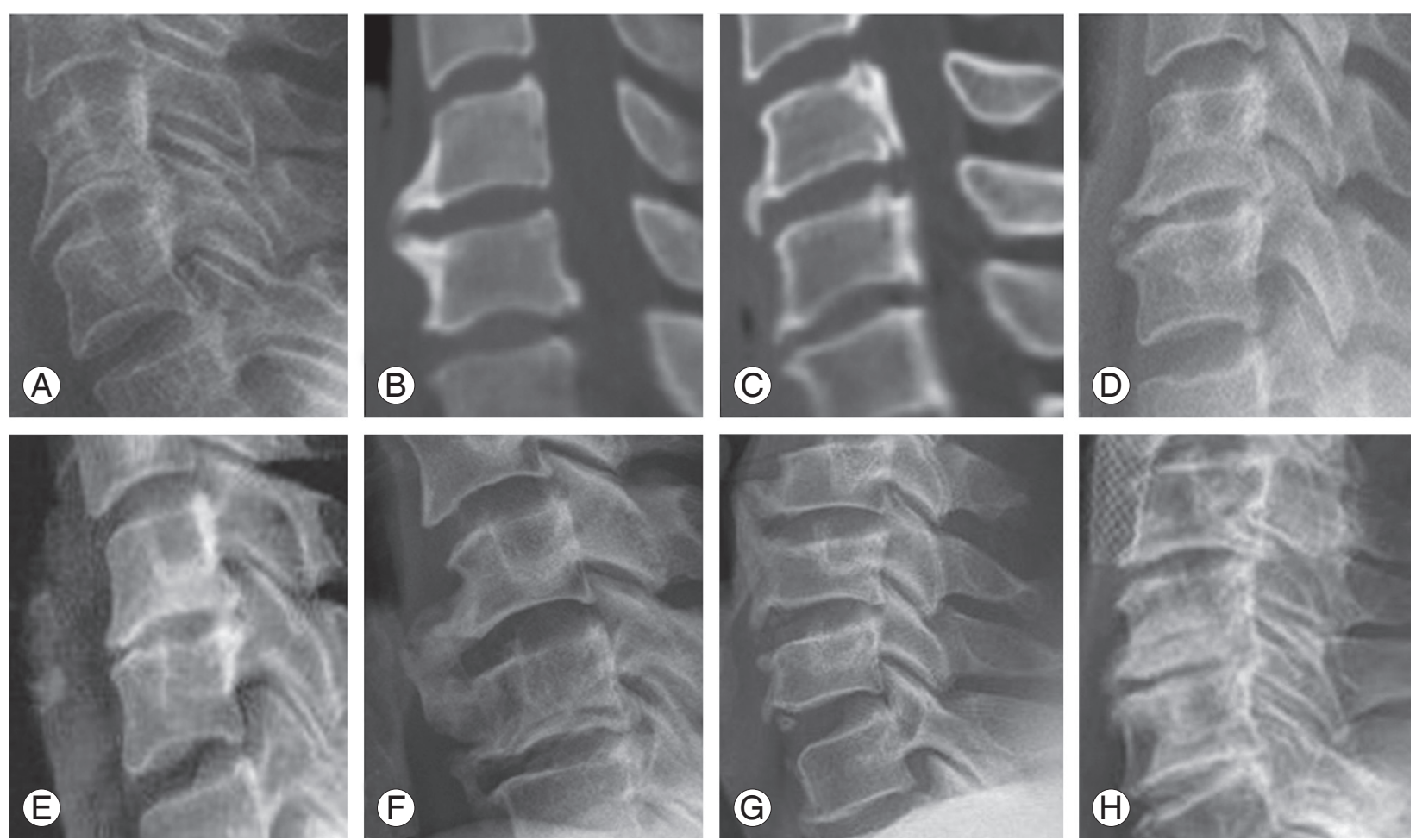

Fig. 9. Various types of spondylophytes. (A) C5 inferior overhanging sharp corporal lip (uncinate) spur with mild disc height collapse. (B) Paired C5 inferior and C6 upper anterior claw spurs without disc height collapse. (C) Large unpaired C5 anterior inferior claw spur and a paired C6 inferior and C7 upper marginal claw spurs. (D) Paired anterior and posterior corporal osteophytes with one-half disc height collapse. (E) Small unpaired C5 inferior spur and relatively large posterior paired claw spurs with one-quarter disc height collapse, discogenic osteosclerosis of C5 inferior end-plate. (F) An example of giant anterior ossicle connected with paired claw spur at C5-6 and paired anterior spurs at C6-7 in a 59-year-old man. (G) Sagittal radiogram in a 58-year-old man shows well preserved C4-5 disc space with a monosegment free "plate-form ossification of anterior longitudinal ligament", presumably the variant ossification of anterior longitudinal ligament, pushing the formed C4 and C5 anterior inferior claw spurs up- and downwardly, and also shows the paired anterior spurs in C6-7 and C7-T1, segments. All disc spaces are well preserved. (H) Cervical radiograms of a 82-year-old man show two level spondylosis $\mathrm{C} 4-5$ and $\mathrm{C} 5-6$ with rather flattened sagittal curve C1-6, and also show anterior and posterior spurs at C4-5 and C5-6, and discogenic subchondral osteosclerosis of caudal half of C5 and upper part of C6.

Table 5. Age-related radiographic incidence of olisthesis, OPLL and OALL in 220 patients with degenerative discs out of 460 patients

\begin{tabular}{|c|c|c|c|c|c|c|c|}
\hline \multirow[b]{2}{*}{ Olisthesis } & \multicolumn{7}{|c|}{ Decades } \\
\hline & $\begin{array}{c}\text { 4th } \\
(n=76)\end{array}$ & $\begin{array}{c}\text { 5th } \\
(n=107)\end{array}$ & $\begin{array}{c}\text { 6th } \\
(n=112)\end{array}$ & $\begin{array}{c}7 \text { th } \\
(n=85)\end{array}$ & $\begin{array}{c}\text { 8th } \\
(n=64)\end{array}$ & $\begin{array}{c}9 \text { th } \\
(n=16)\end{array}$ & Total \\
\hline Ante-listhesis ( $\mathrm{n}=2$ ) & - & - & $C_{5}: 1$ & - & - & $C_{5}: 1$ & 2 \\
\hline Retro-listhesis $(n=4)$ & - & $\begin{array}{l}C_{4}: 1 \\
C_{5}: 1\end{array}$ & $C_{4}: 1$ & - & $C_{3}: 1$ & - & 4 \\
\hline OPLL (n=3) & - & 1 & 2 & - & - & - & 3 \\
\hline OALL $(n=1)$ & - & - & 1 & - & - & - & 1 \\
\hline
\end{tabular}

OPLL, ossification of the posterior longitudinal ligament; OALL, ossification of anterior longitudinal ligament.

while degenerative changes of the facet joints rarely cause the disc space narrowing and foraminal stenosis. Payne and Spillane [8] reported that cervical spine had smaller foramen, which formed the inner wall of the neural fora- men and closely contacted the nerve roots. Thus, spurs of the Luschka's joint are the main cause of the radicular symptoms through the sensory branch [8]. Examination of 70 autopsied cervical spines from patients aged 38 to 

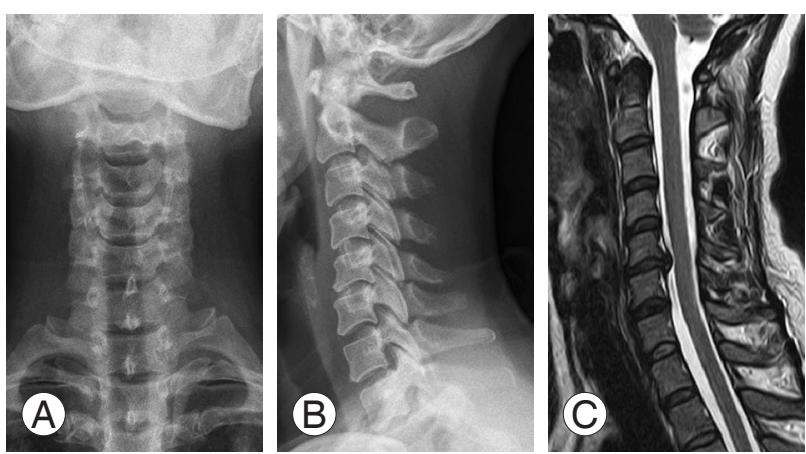

Fig. 10. A 41-year-old woman complained of neck pain and tingling sensation in the left arm. Cervical radiograms show slightly narrowed C5-6 disc space with flattered sagittal curve. No spur or ossicle are seen. Magnetic resonance imaging shows the centrally herniated disc.

95 years at the time of death indicated that degeneration affected the entire cervical spine, which was generally agerelated [21]. The majority (72\%) of specimens from individuals over 70 years of age had several abnormalities; the C5-6 level was the most frequently involved, followed by C6-7 with the C2-3 level least involved. The marked narrowing of the disc was associated with fissures, extending into and becoming continuous with fissures and Luschka's joints. Nuclear material extended under the longitudinal ligament into the Luschka's joints and even into the adjacent vertebral bodies. The Luschka's joints were markedly altered in the lower three levels, most frequently at the C5-6 region. This observation was also made by in another study following anterior cervical interbody fusion [9].

The severity of the degenerative disks, spur and ossicle formation of the anterior ligament and their relationships have not been studied. In the current study, the severity of the degenerative disks ranged widely, but was mostly + to++. Also, the degenerated segments were mostly localized to $\mathrm{C} 4$ to 7 levels (Tables 3, 4). It was assumed that the anterior ligament ossicle and OALL contributed to the stability of the degenerated disc segment, and consequently maintained the normal disk height from collapse (Figs. $8,9,10 \mathrm{G}$ ). There was no necessity of statistical assessment to prove this. Thus, it is thought that ossicle in anterior ligament is a good omen indicating the supporting role of the segment. However, simple radiograms had low diagnostic accuracy in detecting the posterior corporal spur and Luschka's joint arthropathy. Also, it was an interesting finding that anterior corporal edge spurs seldom accompanied the posterior spurs. The age-matched incidences of spondylosis, numbers of spondylotic segments, severity of degenerative disks and cervical curve changes have not been examined. Also, no study has addressed the relationship between the degenerative discs, spurs, anterior ligament ossicle formation and segmental stability. Only in a few cases did the segment with anterior ligament ossicle and disc space became narrowed, while most of the segments with uncinate (anterior inferior edge spur) spurs narrowed. Spurs are thought to have two roles: beneficial stabilizing and disc collapse prevention role for the same segment, and a harmful role in pain provocation and surrounding tissue compression. Anterior corporal marginal claw and traction spur can displace and compress the anterior organs, such as esophagus and trachea, when its size is excessively large, while the posterior ridge spur precipitates clinical symptoms and signs more frequently than the anterior spur in spite of its low incidences and its smaller size. It was thought that ossicle in anterior ligament including OALL has a beneficial role, but not necessarily in all patients. Retrolisthesis developed in four cases in different levels in the current series; one at $\mathrm{C} 3$, two at $\mathrm{C} 4$ and one at C5. This contradicted another report [17]. OPLL seemed not related with the degenerative disks [2].

We could not find age-matched characteristic radiographic images of cervical spondylosis, except the increased severity and increased incidences of degenerate disks and segments according to age increase. The loss of cervical lordosis depended on the severity of disc degeneration, and the numbers of the degenerated disks, and thus there were no age-matched differences in cervical lordosis. The incidences of cervical spondylosis in the Jeju islanders are similar to the mainlanders [11], though their living habits are somewhat different in the females in the past.

The following study limitations are noted. Most important are the lack of longitudinal study for each individual and of gene morphophisms for spurs [23]. Credibility of assessment, accuracy and feasibility in applying the radiographic findings to management, and lack of routine CT, MRI and repeated MRI study with certain intervals are secondary limitations. The lack of information related with age-matched signal changes on MRI that occur within disk over time is another important limitation. Inter- and intra-observer disagreement and difficulty of disc height measurement in MR grading classification system are limitations, although in another study MRI grading provided a reliable assessment of MRI disc morphology [24]. Our view is that MRI classification of disc degenera- 
tion is not superior to the simple radiographic assessment in clinical practice.

Cevical spondylosis in the elderly involves age-related, inevitable and progressive degenerative changes that deteriorate the individual's physical functions including independence, and which progresses further and becomes more symptomatic if not properly cared for.

In spite of the higher incidences of spondylosis, even symptomatic spondylotic patients complaining of shoulder-neck-brachial pain can be well controlled by conservative means, with surgery not needed very often [1416]. However, the high incidences of spondylosis in Jeju islanders suggest that functional health maintenance and protection of the musculoskeletal system of the islanders will be a clinical issue in deterring the progressive decline of physical function and loss of independence. Thus, understanding of the age-related changes in the musculoskeletal function and being able to differentiate those from the other ailment are essential to maintain the function of the spinal column.

In the current study, we did not deal with disease management. However, we think that surgical management, such as decompression and/or fusion surgery, must be the last resort when all the conservative managements fail, given that surgery-related systemic and local complications are rather high in the elderly [16]. In the conservative management of symptomatic spondylosis, pain-relief must be the first step, followed by maintenance of physical independence. Then a specific physical exercise program for elderly individuals should be tailored to the specific needs of the patients and should be designed to offset ageand inactivity-related musculoskeletal changes that minimize the risk of conservative physical therapy.

\section{Conclusions}

Conventional simple cervical radiograms in four projections remains a cost-effective basic imaging study to detect early disc degeneration, and is very reliable diagnostic tool in assessing the degenerative processes of cervical spine, and provides the managing direction of the cervical spine disorder.

\section{Conflict of Interest}

No potential conflict of interest relevant to this article was reported.

\section{References}

1. Key CA. Paraplegia depending on disease of the ligaments of the spine. Guys Hosp Rep 1938;3:17-3.

2. Gowers WR. A manual of diseases of the nervous system. London: Churchill; 1892-93.

3. Borak J. Spondylosis and spondylarthritis. Ann Intern Med 1947;26:427-39.

4. Taylor AR, Blackwood W. Paraplegia in hyperextension cervical injuries with normal radiographic appearances. J Bone Joint Surg Br 1948;30:245-8.

5. Nathan H. Osteophytes of the vertebral column. J Bone Joint Surg Am 1962;44:243-68.

6. De Palma AF, Rothman RH. The intervertebral disc. Philadelphia: WB Saunders; 1970.

7. Pallis C, Jones AM, Spillane JD. Cervical spondylosis; incidence and implications. Brain 1954;77:274-89.

8. Payne EE, Spillane JD. The cervical spine; an anatomico-pathological study of 70 specimens (using a special technique) with particular reference to the problem of cervical spondylosis. Brain 1957;80:57196.

9. Smith GW, Robinson RA. The treatment of certain cervical-spine disorders by anterior removal of the intervertebral disc and interbody fusion. J Bone Joint Surg Am 1958;40:607-24.

10. Lawrence JS. Disc degeneration: its frequency and relationship to symptoms. Ann Rheum Dis 1969;28: 121-38.

11. Moon MS, Kim I, Han IH. A clinical study of cervical spondylosis. J Korean Orthop Assoc 1973;8:29-38.

12. Moon MS KI, Kim BK, Kim DW. Radiographic measurement of normal and spondylotic cervical spine in the Korean population. J Korean Orthop Assoc 1977; 12:9-212.

13. Moon MS, Ha KY, Jeong DY. Pavlov's ratio of cervical spine of normal Koreans: determining spinal stenosis on routine related roentgenograms. J Korean Orthop Assoc 1989;24:1307-12.

14. Torrens M. Cervical spondylosis Part 1: Pathogenesis, diagnosis and management options. Curr Orthop 1994; 8:255-64.

15. Yue WM, Tan SB, Tan MH, Koh DC, Tan CT. The Torg--Pavlov ratio in cervical spondylotic myelopathy: a comparative study between patients with cervical spondylotic myelopathy and a nonspondylotic, nonmyelopathic population. Spine (Phila Pa 1976) 
2001;26:1760-4.

16. Ryu JS, Chae JW, Cho WJ, Chang H, Moon MS, Kim SS. Cervical myelopathy due to single level prolapsed disc and spondylosis: a comparative study on outcome between two groups. Int Orthop 2010;34:10115.

17. Hayashi K, Yabuki T. Origin of the uncus and of Luschka’s joint in the cervical spine. J Bone Joint Surg Am 1985;67:788-91.

18. Wilkinson M. Cervical spondylosis [dissertation]. Oxford: Oxford University; 1959.

19. Friedenberg ZB, Miller WT. Degenerative disc disease of the cervical spine. J Bone Joint Surg Am 1963; 45:1171-8.
20. Epstein E. The spine. 2nd ed. Philadelphia: Lee and Febinger; 1969.

21. Macnab I. The traction spur: an indicator of segmental instability. J Bone Joint Surg Am 1971;53:663-70.

22. Epstein BS, Epstein JA, Jones MD. Cervical spinal stenosis. Radiol Clin North Am 1977;15:215-26.

23. Sakai Y, Matsuyama Y, Hasegawa Y, et al. Association of gene polymorphisms with intervertebral disc degeneration and vertebral osteophyte formation. Spine (Phila Pa 1976) 2007;32:1279-86.

24. Pfirrmann CW, Metzdorf A, Zanetti M, Hodler J, Boos N. Magnetic resonance classification of lumbar intervertebral disc degeneration. Spine (Phila $\mathrm{Pa}$ 1976) 2001;26:1873-8. 